\title{
UNSTEADY RAH-66 COMANCHE FLOWFIELD SIMULATIONS INCLUDING FAN-IN-FIN
}

\author{
Emre Alpman ${ }^{*}$ \\ exa152@psu.edu \\ The Pennsylvania State University \\ Lyle N. Long ${ }^{\dagger}$ \\ lnl@psu.edu \\ The Pennsylvania State University
}

\begin{abstract}
Understanding the dynamic relationship between the antitorque moment thrust and the applied collective pitch angle is crucial especially for directional control sensitivity analyses. Although there are many studies in the literature on the steady state behavior of the FANTAIL $^{\text {TM }}$, little is known about the transient response and thrust build up, which is the primary focus of this paper. Computational fluid dynamics is used for the solutions here, because it provides a more complete flowfield prediction, especially in low-power, near edge-wise conditions. The flowfield is assumed to be inviscid and the Euler equations are solved with a blade element model for the FANTAIL ${ }^{T M}$. The main rotor is excluded in this study. Solutions are obtained by modifying the computer code PUMA2 (Parallel Unstructured Maritime Aerodynamics), and using an unstructured grid of 2.8 million cells. It was run on the Beowulf clusters COCOA2 and COCOA3. Dynamic fan thrust and moment response to applied collective pitch in hover and forward flight are presented and discussed.
\end{abstract}

\section{INTRODUCTION}

Experience on the RAH-66 Comanche has shown that, despite substantial improvements in momentumtype models of the steady thrust response of a ducted tail rotor $^{1}$, the dynamics of the total (fan + shroud) thrust response in forward flight are not yet well understood. The unexpected thrust response was first clearly observed in flight tests shortly after the initial engagement of the Core Automatic Flight Control System (CAFCS) mode. Figure 1 shows a sustained, large-amplitude $1-\mathrm{Hz}$ yaw oscillation during a shallow turning partial-power descent at 80 knots forward speed. (There were no loads or safety issues associated with this oscillation, but it would obviously adversely affect pilot comfort.) Notice that the average (trim) value of the FANTAIL ${ }^{\mathrm{TM}}$ pitch is near zero, where the mass flux through the duct is near zero.

After an exhaustive review of possible causes of the oscillations, including a careful audit of digital processing delays and consideration of stiction in the actuators, among many other factors, the conclusion was reached that there must be a significant apparent delay in the development of thrust in response to collective pitch changes.

This study was performed to simulate the unsteady flow around the fuselage of an RAH-66 Comanche helicopter and to analyze the effects of varying the collective pitch angle. The main goal was to improve the understanding of the dynamic relationship between the ducted tail rotor and the applied collective pitch, which is important in control sensitivity analyses.

\footnotetext{
* AIAA Student Member, Graduate Assistant

${ }^{\dagger}$ AIAA Associate Fellow, Professor

Copyright (C) 2003 by Emre Alpman, The Pennsylvania State University. Published by the American Institute of Aeronautics and Astronautics, Inc. with permission.
} 

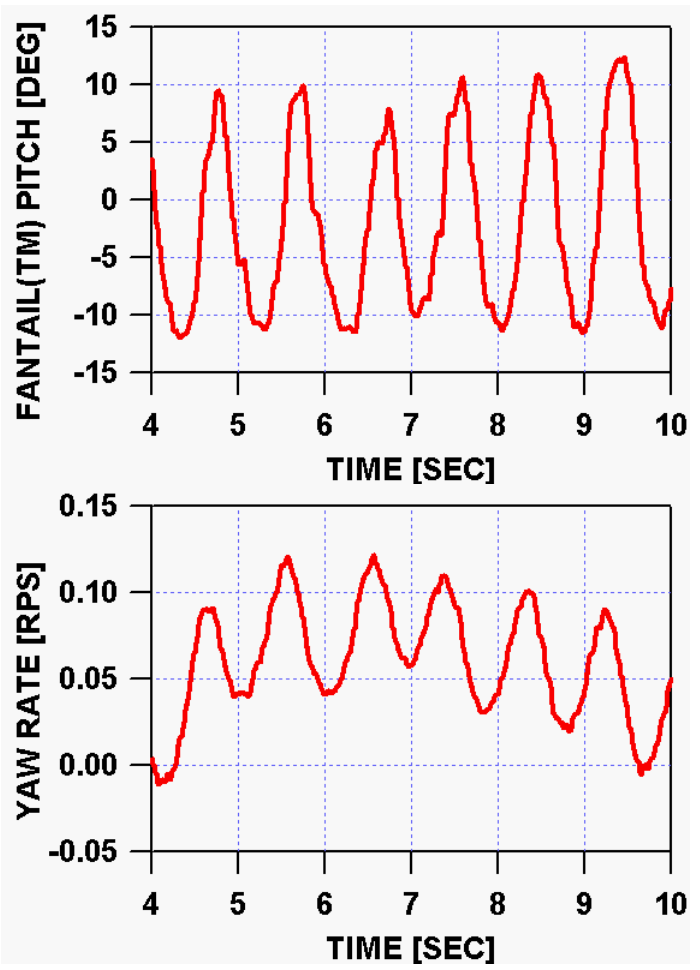

Figure 1. Sustained 1-Hz Directional Axis Oscillation in Shallow Turning Partial Power Descent at 80 Knots.

\section{METHODOLOGY}

The aim of this study is to simulate the flowfields around the RAH-66 Comanche helicopter and to analyze the effects of varying the collective pitch angle of the fan blades on the development of aerodynamic forces and moments. Computational fluid dynamics is used for this purpose because it allows a more complete mathematical model to make quantitative predictions of complex flows dominated by non-linear effects ${ }^{2}$. Researchers have employed potential flow theory ${ }^{3,4}$, Euler equations ${ }^{5,6}$, and Navier-Stokes equations ${ }^{3,7,8,9}$ to define the flowfield around helicopters. Each of these methodologies has an associated computational and setup cost/benefit ${ }^{7}$. In this study the flowfield is assumed to be inviscid and the predictions are made using Euler equations. The antitorque system of the helicopter, which is a ducted fan designated as the FANTAIL ${ }^{\text {TM }} 10$, is modeled using an actuator disk, in which the fan-infin is assumed to be a rotor with zero thickness ${ }^{11}$. The effects of the FANTAIL ${ }^{\mathrm{TM}}$ are introduced to the flow as boundary conditions in which the pressure undergoes a discontinuity while the other flow parameters remain continuous. For our purposes here, detailed modeling of the tip-gap region or blade swirl is assumed to be not critical, therefore they are simply neglected. The local pressure jump at every point on the rotor disk is computed by using blade element theory, which relates the local lift on a differential element of the blade to the local velocity and local blade pitch. While the actual pressure jump at a given location will vary between zero and a maximum pressure difference over the blade chord, in this study averaged values during a single blade passage time are used. While the fan blades could be modeled in more detail, the current method not only requires minimal CPU time but also provides excellent correlation with fan thrust experimental data ${ }^{12}$ in hover and sideward flight ${ }^{5}$. The collective pitch angle used in this study refers to the local blade pitch at $75 \%$ radius.

Computations are presented here for hover and forward flight conditions. The governing equations are solved on an unstructured grid of 2.8 million tetrahedral cells, which can be seen in Figure 2.

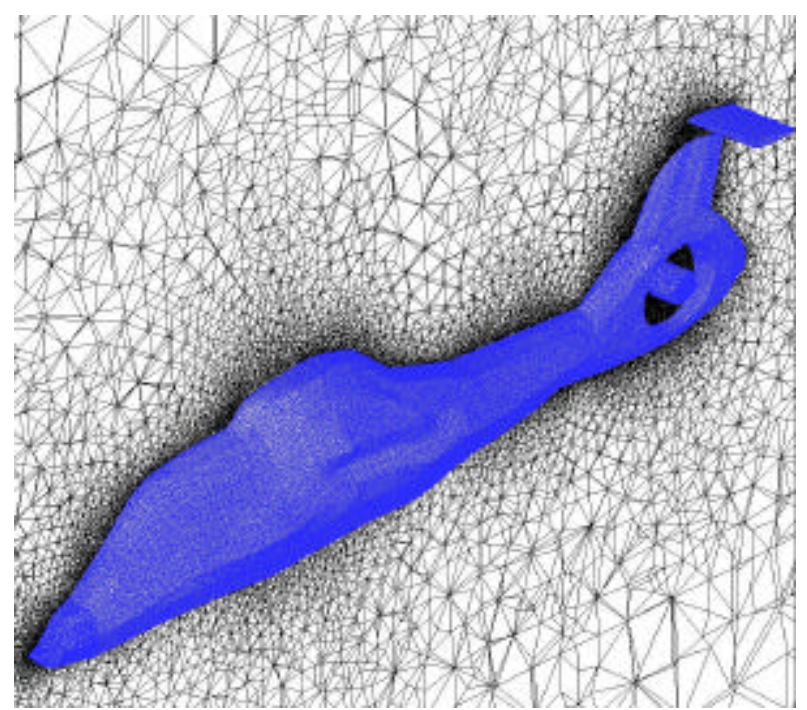

Figure 2. Sectional view of the computational mesh.

$$
(\mathrm{y} / \mathrm{L}=0.0)
$$

Numerical solutions are performed by modifying the computer code PUMA2 (Parallel Unstructured Maritime Aerodynamics), which is a computer program for analysis of internal and external non-reacting compressible flows over arbitrarily complex 3D geometries. Written entirely in ANSI C and using the $\mathrm{MPI}^{13}$ library (message passing interface) for parallel processing, PUMA2 is based on the finite volume method and supports mixed topology unstructured 
grids, composed of tetrahedral, wedges, pyramids and hexahedra. The code may be run so as to preserve time accuracy or as a pseudo-unsteady formulation to enhance convergence to steady state (using GaussSeidel or SOR). Dynamic memory allocation used in the code also makes the problem size limited only by the amount of memory available on the machine. PUMA2 has been used and validated by Long et al. for the numerical solution of numerous problems ${ }^{5,14-16}$. In the current study the finite volume method with Roe's flux difference splitting scheme is employed along with the four-stage Runge-Kutta type time integration technique. The code is run on the Beowulf clusters COCOA $2^{15,23,26,27}$, and COCOA3.

\section{RESULTS}

The results illustrate the transient response of aerodynamic forces and moments to changes in the collective pitch settings in hover and forward flight. In the studies the pitch angle is changed by 5 degrees from an equilibriumpoint at a rate of 144 degrees per second and the development of the fan thrust and yawing moment are analyzed.

Preliminary studies were performed by changing the pitch angle from 20 degrees to 15 degrees for hover and for forward flight (150 knots). Figures 3 to 6 show the variations of collective pitch angle, fan thrust, total yawing moment and yawing moment components due to fan and fuselage with time, respectively.

Hover, $? .75=20^{\circ} ? 15^{\circ}$ :

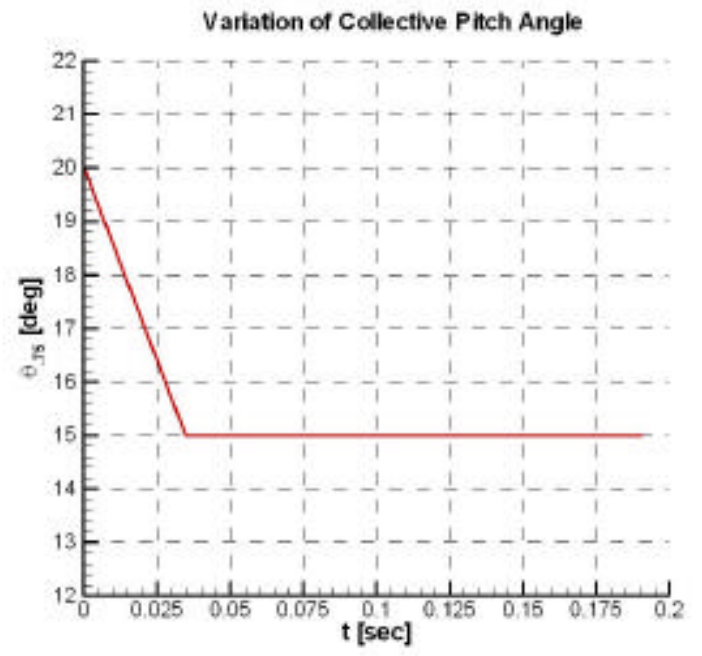

Figure 3. Variation of collective pitch angle with time.

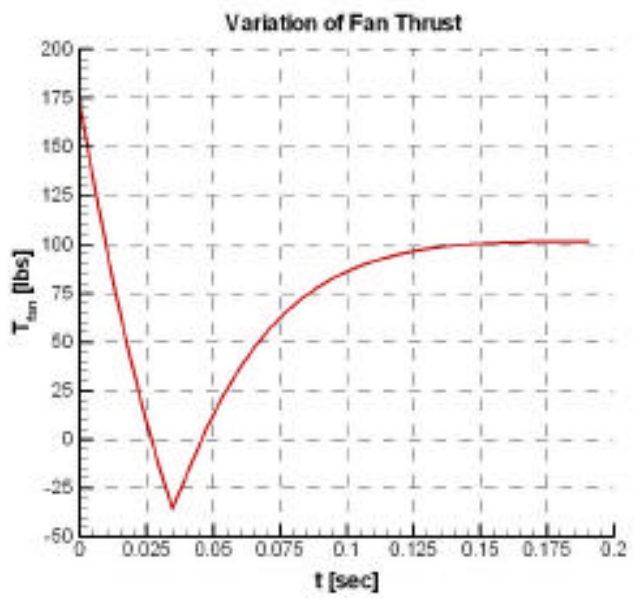

Figure 4. Variation of fan thrust with time.

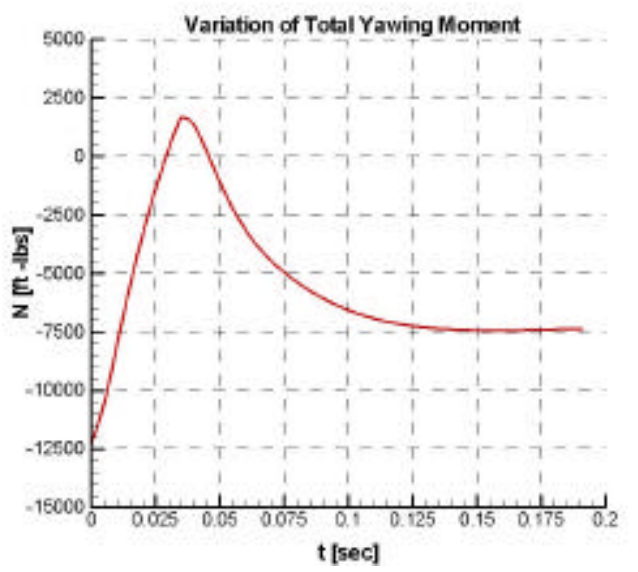

Figure 5. Variation of total yawing moment with time.

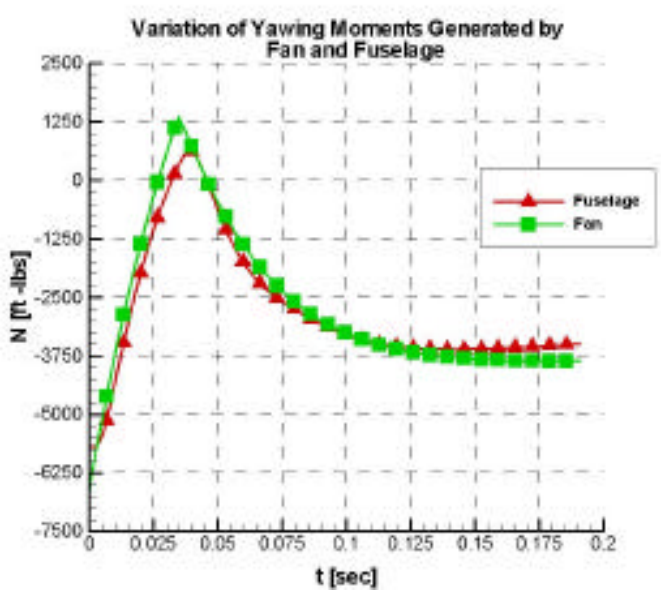

Figure 6. Variations of yawing moment components due to fan and fuselage with time. 
A rapid decrease of the pitch angle decreases the angle of attack of the blades, and consequently the fan thrust. A decrease in fan thrust will also decrease the induced velocity, which will result in increasing the blade angle of attack and the fan thrust. Due to the inertia of the fluid, the induced flow does not respond as quickly as the pitch settings, thus an overshoot and then decay to a steady state value is observed (Figure 4). The thrust generated by the shroud also shows a similar behavior which can be seen in Figure 6. The transient response of fan thrust and yawing moment in forward flight for the same pitch input are displayed in Figures 7, 8 and 9.

Forward Flight, $\mathrm{V}=150 \mathrm{knots}, ? .75=20^{\circ} ? 15^{\circ}$ :

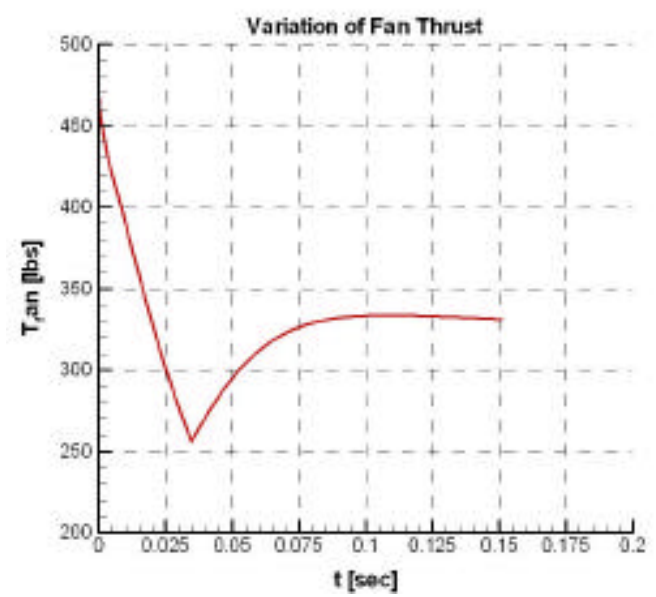

Figure 7. Variation of fan thrust with time.

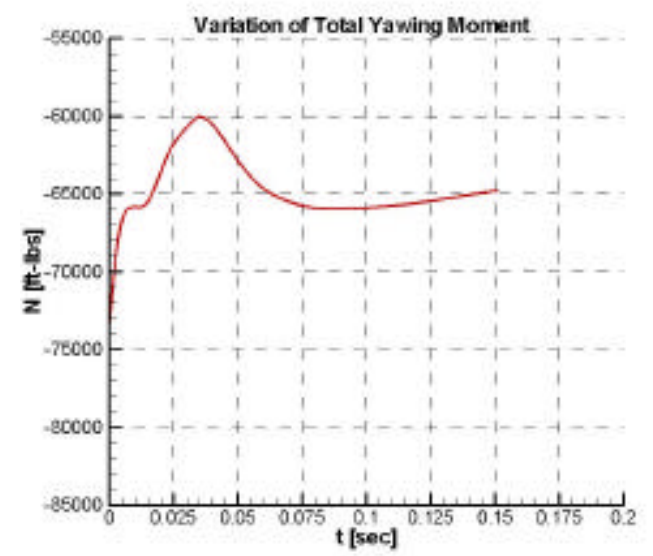

Figure 8 . Variation of total yawing moment with time.

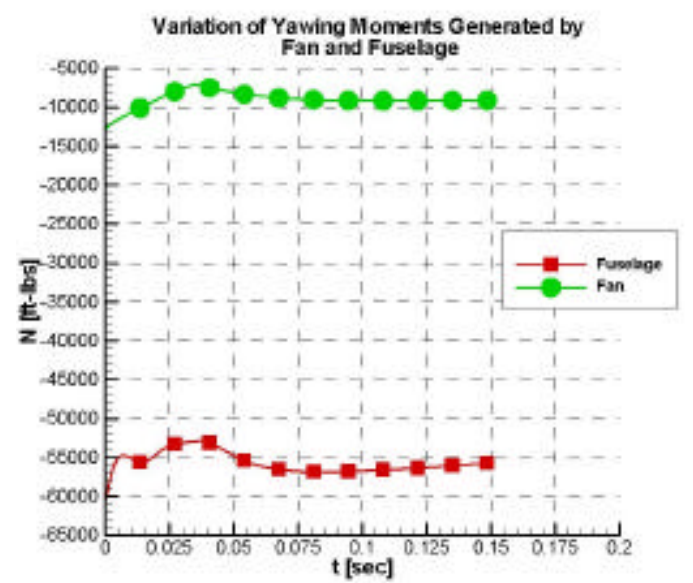

Figure 9. Variations of yawing moment components due to fan and fuselage with time.

Figure 7 shows that the response is qualitatively similar to the hover case but with a smaller overshoot. Unlike hover, in which fan and shroud are the dominating contributors of the antitorque moment, now other parts of the helicopter, such as the vertical tail, also contributes to the yawing moment. This situation can be clearly seen in Figure 9.

It is evident that with the forward speed the vertical tail generates a significant amount of antitorque moment. But the contribution, and transient behavior, of each component is still not obvious. Therefore, a more detailed analysis was performed to simulate the unsteady response of forces and moments generated by the fan, empennage, shroud, vertical tail, and horizontal tail. Since the nominal operating condition for the FANTAIL $^{\mathrm{TM}}$ is near zero pitch angle, a new case is analyzed by changing the collective pitch angle from zero to five degrees at 144 degrees per second. Variations of collective pitch angle, fan thrust, total yawing moment and yawing moments generated by different components in forward flight are shown in Figures 10, 11, 12, and 13. The time history of the average inflow velocity can be seen in Figure 14. It is clear from Figure 11 that fan thrust shows a qualitatively similar response to the previous case but now with more oscillatory behavior. Figure 14 also supports the explanation for this response. After the collective pitch angle stops changing, the average inflow velocity continues to increase and then to decrease, which effectively first decreases then increases the local blade angle of attack. 
Forward Flight, $\mathrm{V}=150$ knots, ? $75=0^{\circ} ? 5^{\circ}$ :

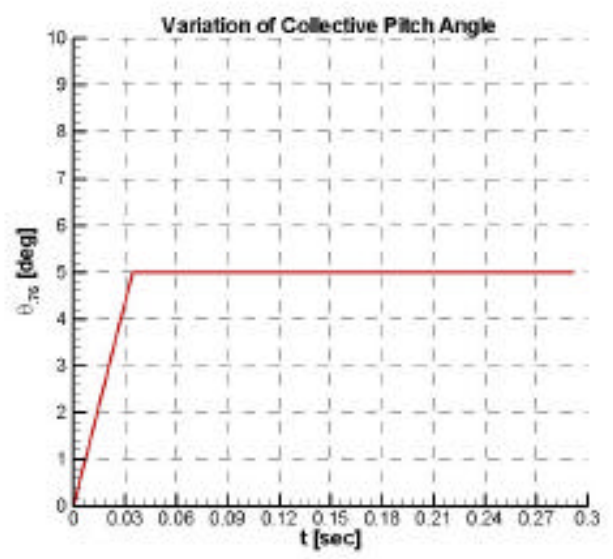

Figure 10. Variation of collective pitch angle with time.

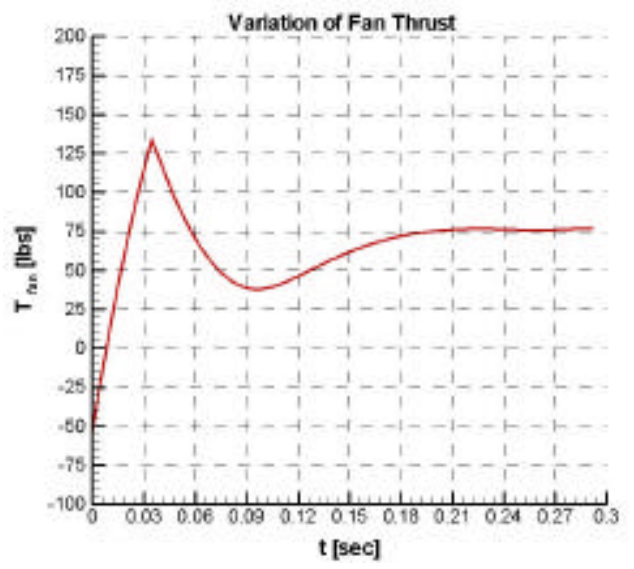

Figure 11. Variation of fan thrust with time.

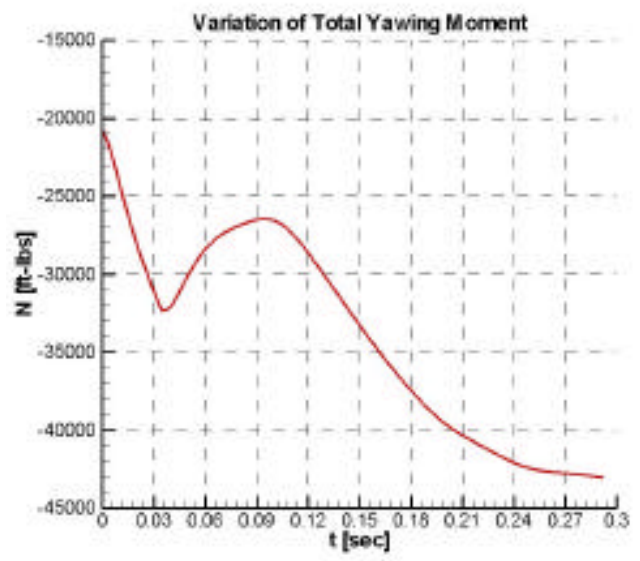

Figure 12. Variation of total yawing moment with time.

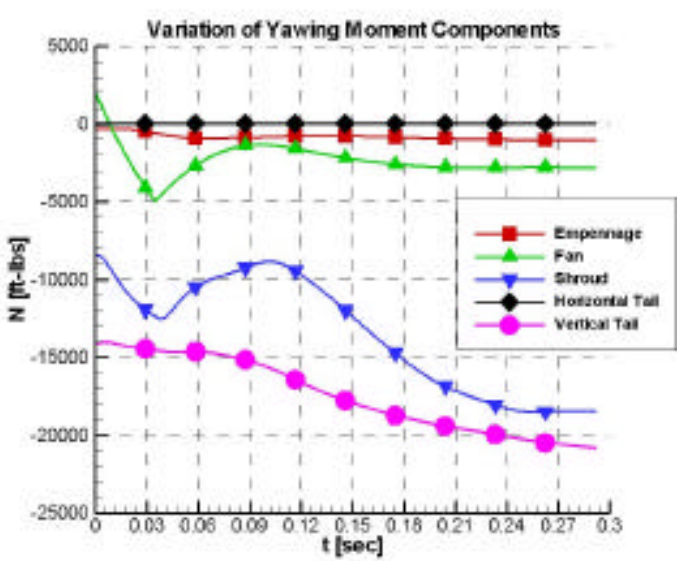

Figure 13. Variations of yawing moment components with time.

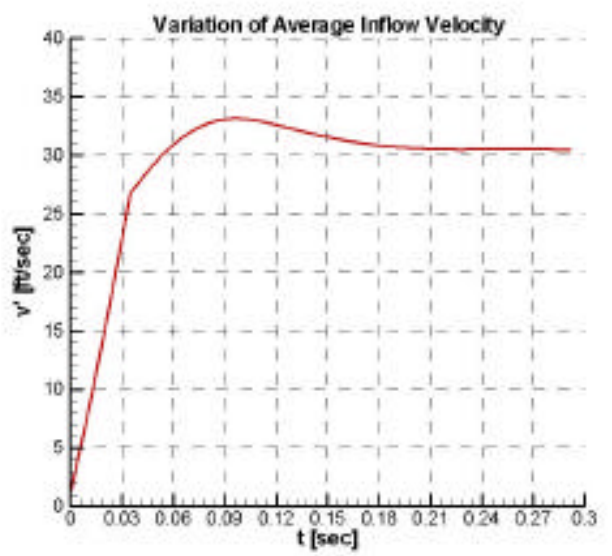

Figure 14. Variation of average inflow velocity with time.

As mentioned earlier, with the introduction of forward speed other components of the fuselage start to generate a significant amount of yawing moment. This situation can be seen in Figure 13. It is evident that the shroud and the vertical tail are the dominating components for the yawing moment. They also significantly affect the transient response of the total yaw moment which can be observed in Figure 12. For a better understanding of the yawing moment behavior of shroud and the vertical tail, surface pressure distributions of the FANTAIL ${ }^{\mathrm{TM}}$ are displayed in Figures 15 to 20.

American Institute of Aeronautics and Astronautics 

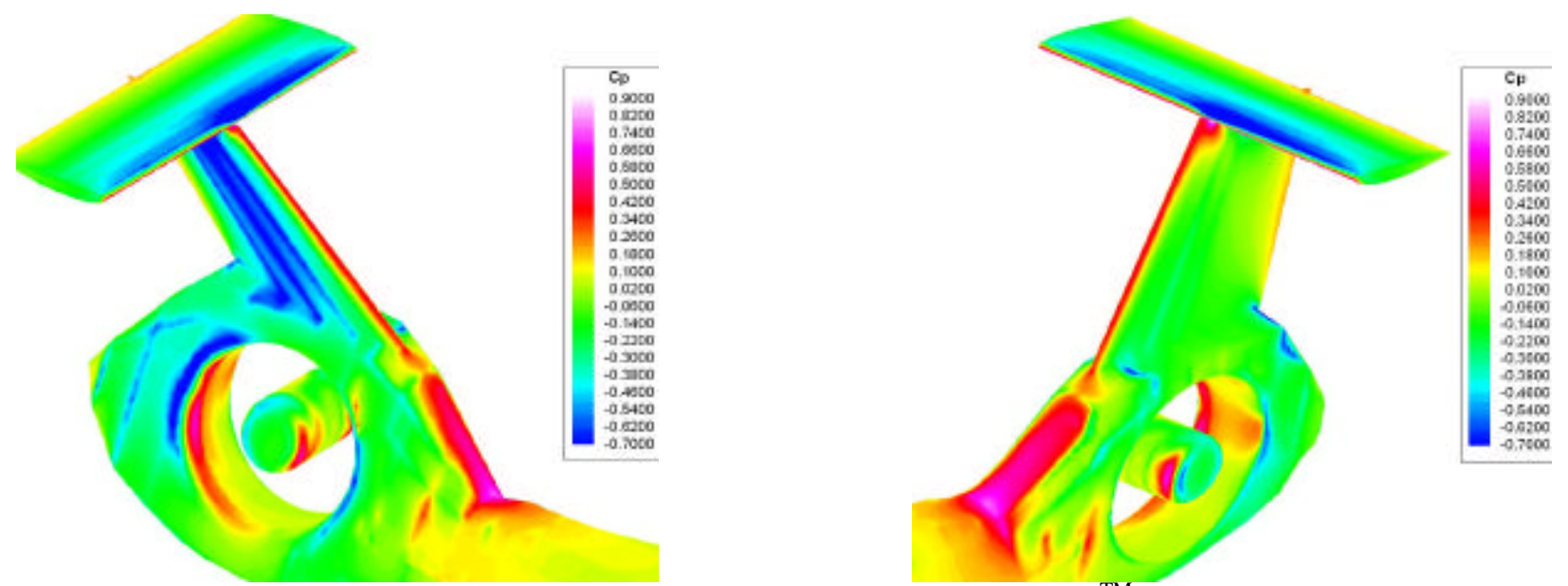

Figure 15. Pressure distribution around FANTAIL ${ }^{\mathrm{TM}}$

(Forward flight, $\mathrm{V}=150$ knots, $\mathrm{t}=0.011 \mathrm{sec}$ )
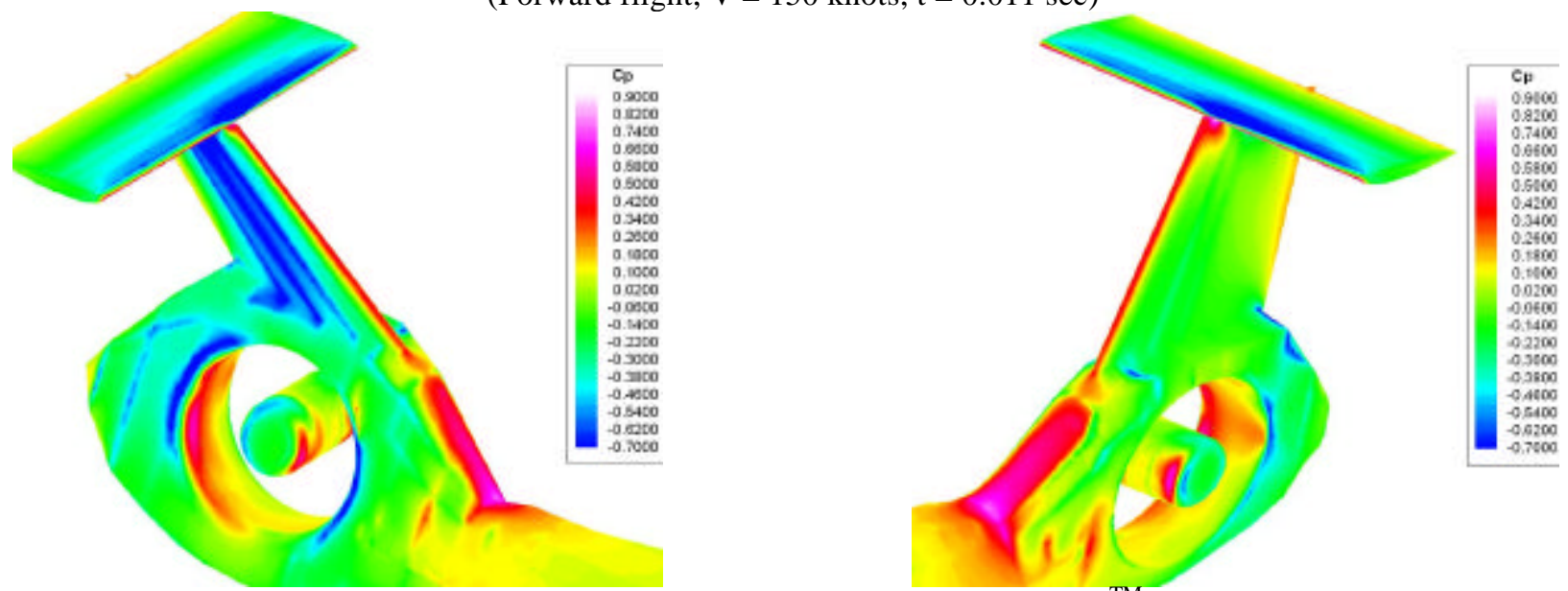

Figure 16. Pressure distribution around FANTAIL ${ }^{\mathrm{TM}}$

(Forward flight, $\mathrm{V}=150$ knots, $\mathrm{t}=0.034 \mathrm{sec}$ )
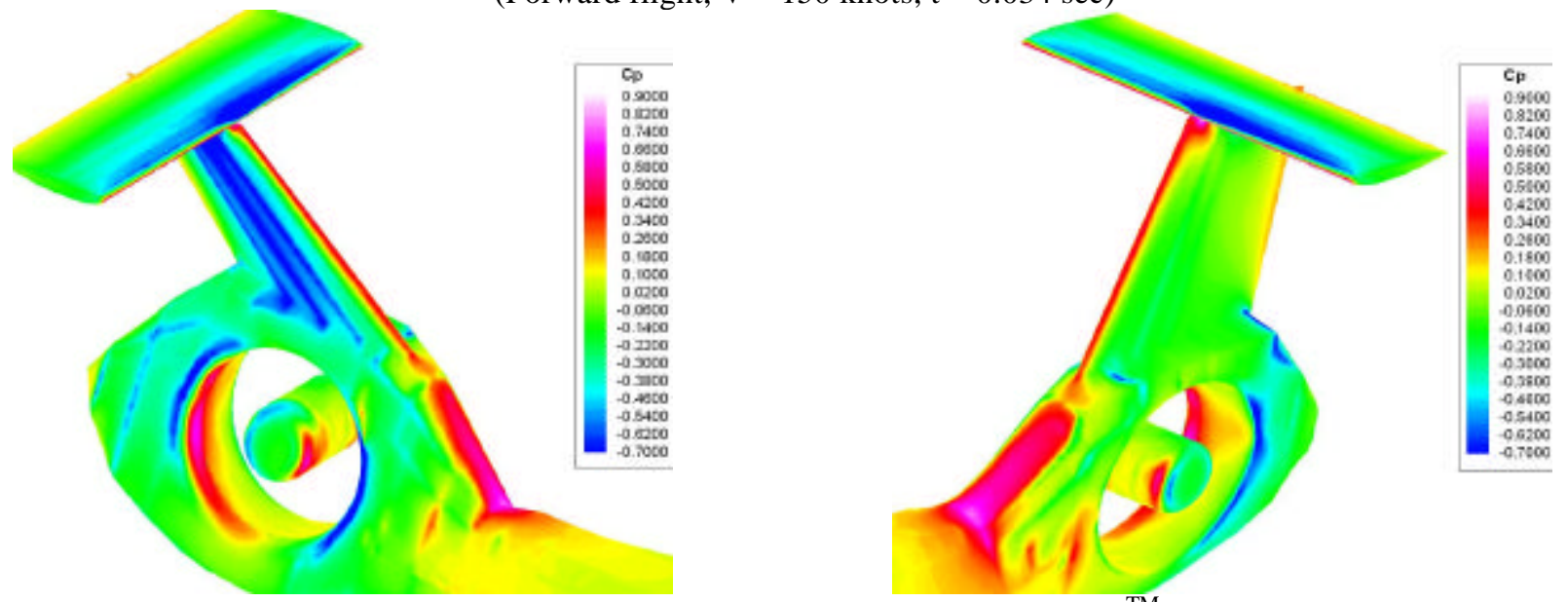

Figure 17. Pressure distribution around FANTAIL ${ }^{\mathrm{TM}}$

(Forward flight, $\mathrm{V}=150$ knots, $\mathrm{t}=0.058 \mathrm{sec}$ )

American Institute of Aeronautics and Astronautics 

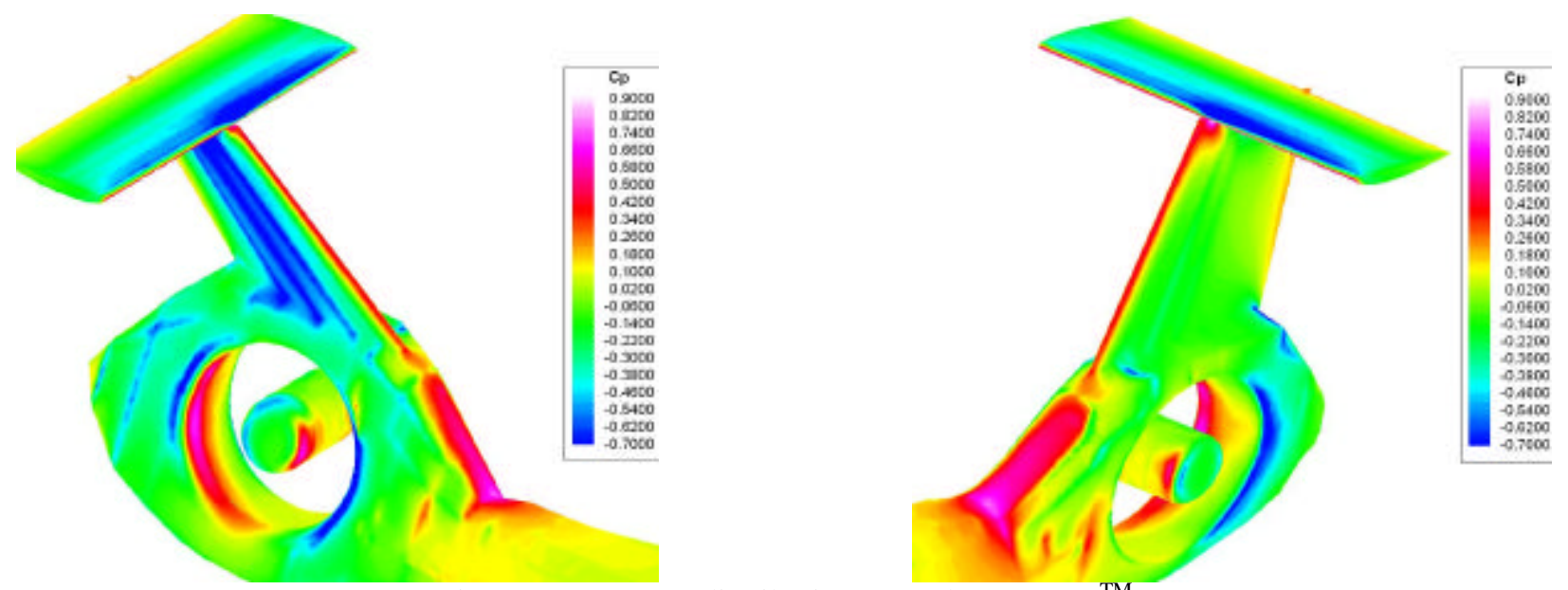

Figure 18. Pressure distribution around FANTAIL ${ }^{\mathrm{TM}}$

(Forward flight, $\mathrm{V}=150$ knots, $\mathrm{t}=0.077 \mathrm{sec}$ )
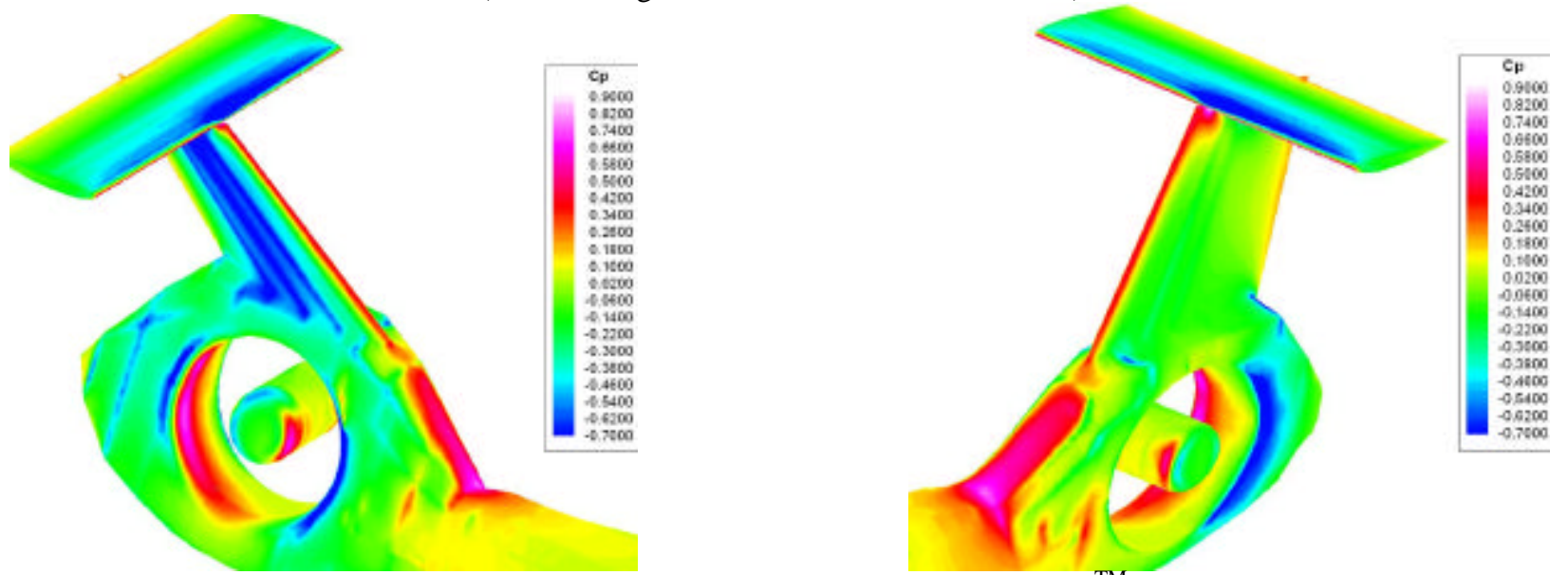

Figure 19. Pressure distribution around FANTAIL ${ }^{\mathrm{TM}}$

(Forward flight, $\mathrm{V}=150$ knots, $\mathrm{t}=0.1 \mathrm{sec}$ )
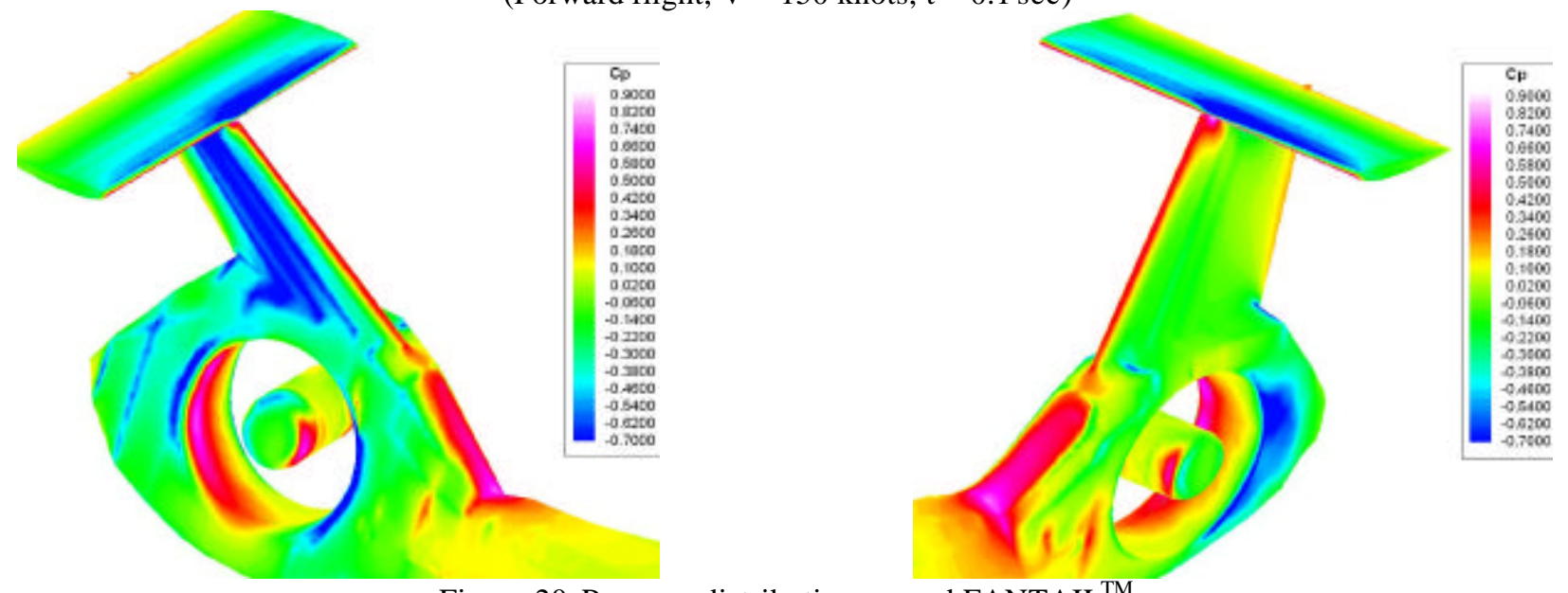

Figure 20. Pressure distribution around FANTAIL ${ }^{\mathrm{TM}}$

(Forward flight, $\mathrm{V}=150$ knots, $\mathrm{t}=0.128 \mathrm{sec}$ )

American Institute of Aeronautics and Astronautics 
An analysis of Figures 15 to 20 yields several conclusions. Initially, the rapid increase of the blade pitch angle creates suction which results in a low pressure region on the upstream lip of the starboard side. This increases the yawing moment generated by the shroud. But as the flow develops, after the new pitch angle is set, the pressure in the vicinity of downstream lip of the shroud begins to increase. This not only decreases the side force developed, but it also moves it more forward. This results in a low yawing moment. In addition to this, as time passes the pressure on the downstream part of the port side begins to decrease, which also effectively decreases the antitorque moment. Figure 20 shows that the pressure in this region begins to increase and cause an oscillatory behavior.

It can also be observed from the figures that the pressure on the starboard side of the vertical tail decreases gradually, which creates a smooth gradual increase in the antitorque moment created by this component.

The results for forward flight show that, at low pitch angles, convergence to the steady state value is slower. In order to further analyze this situation two additional flowfield solutions were performed for hover. In the first one the collective pitch angle is changed from zero to five degrees and in the second one from 35 to 40 degrees at 144 degrees per second. The time histories of collective pitch angle, fan thrust, yawing moments and average inflow velocity for the first case are shown in Figures 21 to 25 .

\section{Hover, ?.75 $=0^{\circ} ? 5^{\circ}$ :}

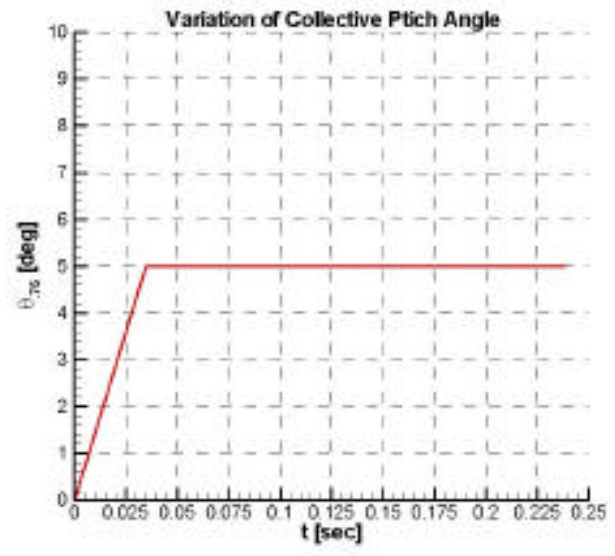

Figure 21. Variation of collective pitch angle with time.

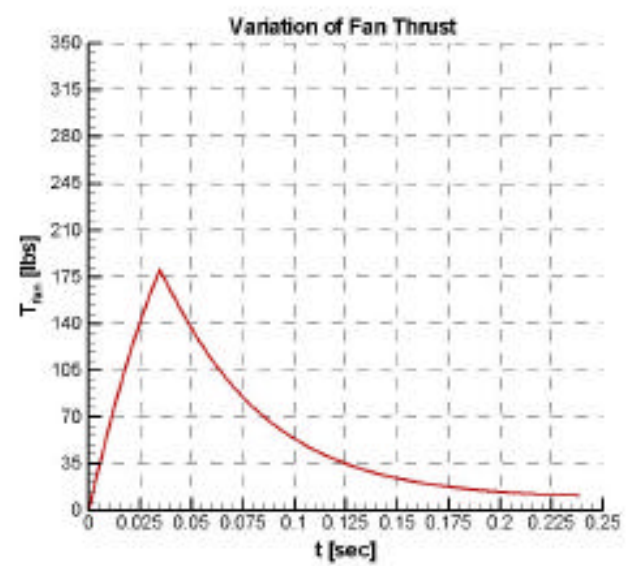

Figure 22. Variation of fan thrust with time.

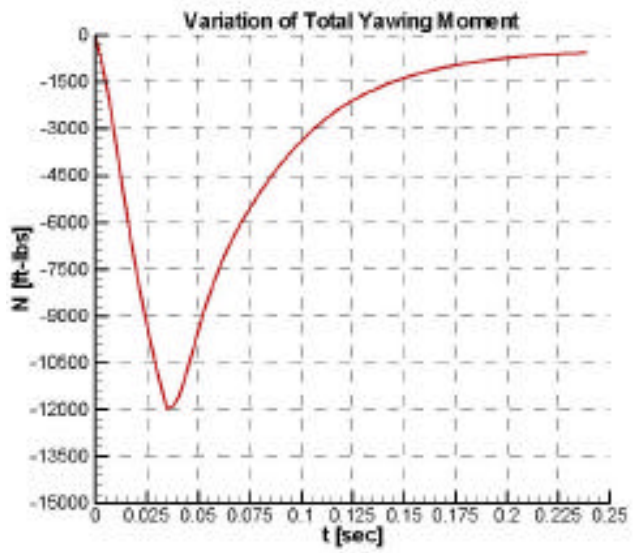

Figure 23. Variation of total yawing moment with time.

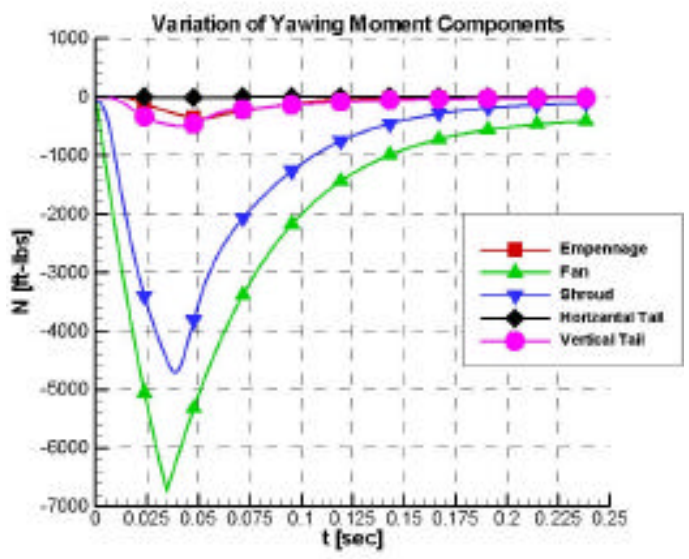

Figure 24. Variations of yawing moment components with time. 


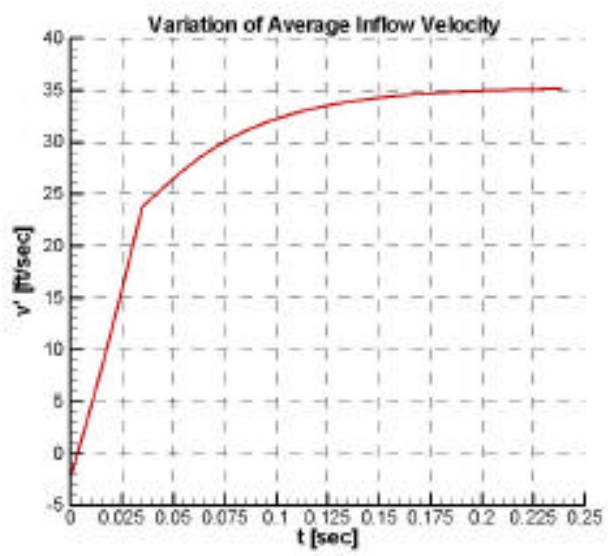

Figure 25. Variation of average inflow velocity with time.

Time histories of collective pitch angle, fan thrust, yawing moments and average inflow velocity for the second case are shown in Figures 26 to 30.

Hover, $? .75=35^{\circ} ? 40^{\circ}$ :

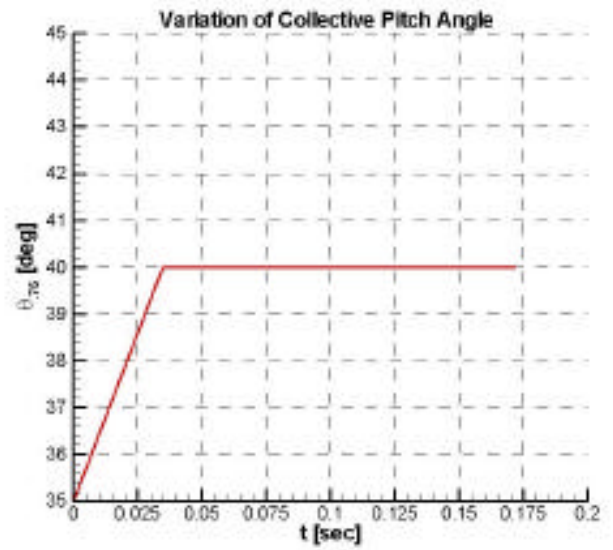

Figure 26. Variation of collective pitch angle with time.

Figures 22, 23, 27 and 28 show that for the same amount of change in the collective pitch angle, a higher overshoot is observed at lower thrust values. In addition to this, convergence to a steady state value is also slower for the low thrust case. Unlike forward flight, the fan is the dominant component for antitorque moment in hover. This situation becomes more severe as the collective pitch angle increases as can be seen from Figures 24 and 29.

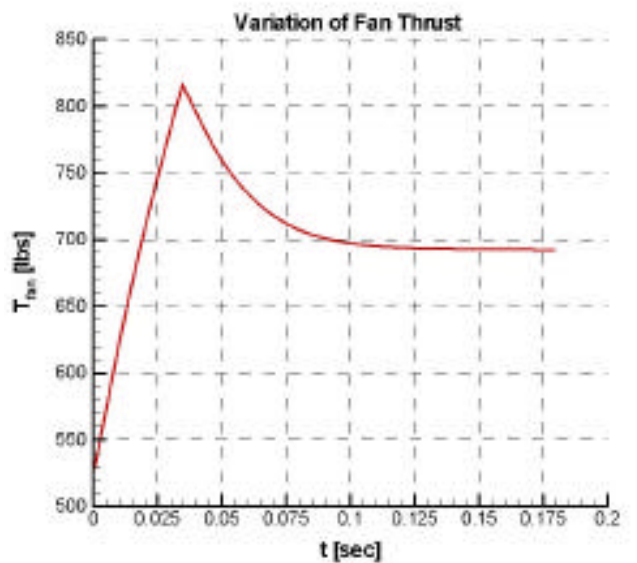

Figure 27. Variation of fan thrust with time (hover)

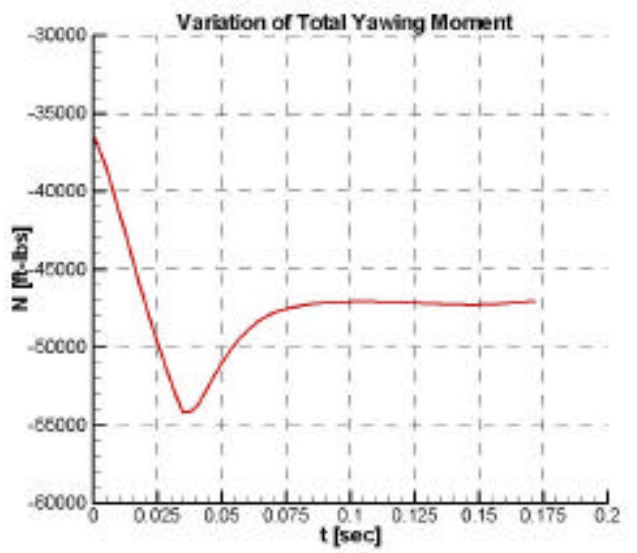

Figure 28. Variation of total yawing moment with time. (hover)

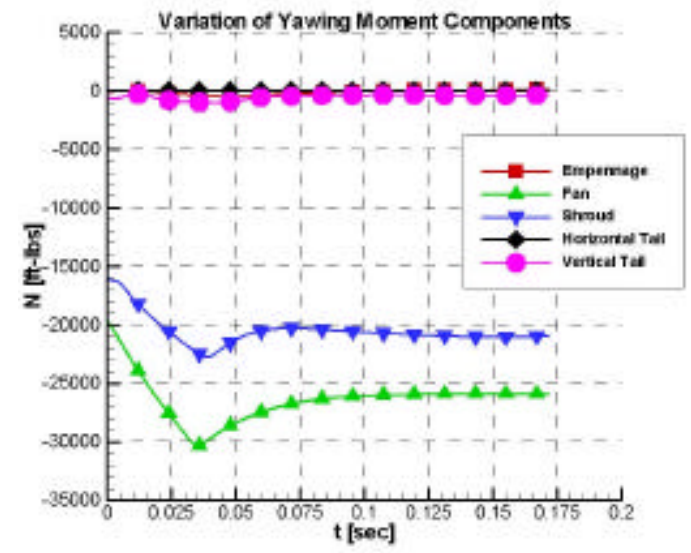

Figure 29. Variation of yawing moment components with time. (hover)

American Institute of Aeronautics and Astronautics 


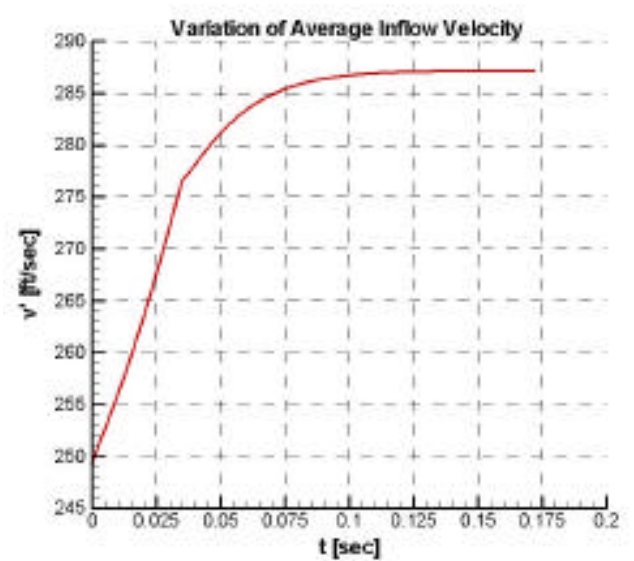

Figure 30. Variation of average inflow velocity with time. (hover)

\section{CONCLUSION}

Numerical simulations of unsteady flowfields around the RAH-66 Comanche helicopter for hover and forward flight, and an analysis of the transient response of fan thrust, yawing moment and average inflow velocity were presented. In the solutions the FANTAIL $^{\mathrm{TM}}$ is modeled by coupling a blade ele ment method with computational fluid dynamics, in which the fan thrust is computed as a function of collective pitch setting and local velocity field. In the solutions the pitch angle is changed by 5 degrees from some equilibrium point at a rate of 144 degrees per second and the transient response of fan thrust, and antitorque moment were obtained. These relations are important in understanding the directional control sensitivity of the helicopter.

The results showed that, in hover, more overshoot is observed in the thrust response at low pitch settings. In addition to this, convergence to steady state was also slower for low thrust case. In hover, as expected, the dominant component for the antitorque moment was the fan. The shroud also generates a significant amount of yawing moment, nearly as much as the fan. The difference between the moments generated by fan and shroud, which also grows as the pitch setting increases, may be a result of the linear lift curve slope as sumption made in the blade element theory. The introduction of the forward speed clearly makes the vertical tail the dominant element for the antitorque moment. The shroud also creates a high amount of yawing moment. The change in collective pitch settings also effectively increases the moments generated by the shroud and vertical tails. In fact the effective increase in vertical tail and shroud components of the antitorque moment were much larger than the fan component. The transient response of fan thrust shows an oscillatory behavior at low thrust levels. The main reason for this response can be said to be the separated and highly vortical flowfield occurring in the duct at zero pitch setting, which is the nominal operating condition of the fan in forward flight.

The results also showed that computational fluid dynamics can be effectively used to obtain static ${ }^{5}$ and dynamic FANTAIL ${ }^{\mathrm{TM}}$ control effectiveness. The next phase of the study will focus on including the main rotor and apply some directional control laws for the helicopter.

\section{ACKNOWLEDGEMENTS}

We gratefully acknowledge many useful suggestions and comments from Bruce Kothmann at Boeing. We would also like to thank the National Rotorcraft Technology Center (NRTC), NASA, and the U.S. Army for funding Penn State's Rotorcraft Center of Excellence (grant number) We would also like to thank the National Science Foundation for equipment grants (grant number).

\section{REFERENCES}

1. Kothmann, B.D., Ingle, S.J., "RAH-66 Comanche Linear Aeroservoelastic Stability Analysis: Model Improvements and Flight Test Correlation," 54th AHS Forum, Washington, DC, 1998.

2. Jameson, A,. "Successes and Challenges in Computational Aerodynamics", AIAA paper 871184, AIAA $8^{\text {th }}$ CFD Conference, Honolulu, Hawaii, June 1987.

3. Maskew, B., "Prediction of Subsonic Aerodynamic Characteristics - A Code for Low-Order Panel Methods", AIAA paper, 81-0252.

4. Chaffin, M. S., Berry, J. D., "Navier-Stokes and Potential Theory Solutions for a helicopter Fuselage and Comparison with Experiment" ATCOM Technical Report 94-A-013, June 1994.

5. Alpman, E., Long, L. N., Kothmann, B. D., "Toward a Better Understanding of the Ducted Rotor Antitorque and Directional Control in Forward Flight", 59 ${ }^{\text {th }}$ AHS Forum, Phoenix, AZ, May 2003.

6. Lee, R. A., Dash, S. M., "Helicopter Plume Flowfield Simulations for Signature Prediction in 
SPIRITS-HC", 20 $0^{\text {th }}$ JANNAF Exhaust Plume Technology Meeting, Philips Lab., Kirtland AFB, NM, February 1993.

7. Duque E. P. N., Dimanlig, A. C. B., "NavierStokes Simulation of the AH-66 (Comanche) Helicopter", AHS Aeromechanics Specialists Conference, San Francisco, CA, January 1994.

8. Duque, E.P.N., Berry, J.D., Budge, A.M., Dimanlig, A.C.B., "A Comparison of Computed and Experimental Flowfields of the RAH-66 Helicopter", AHS Aeromechanics Specialists Meeting, Fairfield Country, Connecticut, October 1995.

9. Costes, M., Collercandy, R., Kroll, N., von Geyr, H. F., Renzoni, P., Amato, P., Kokkalis, A., Rocchetto, A., Serr, C., Larrey, E., Filippone, A., Wehr, D., "Navier-Stokes Calculations of Helicopter Fuselage Flowfield and Loads", AHS $54^{\text {th }}$ Annual Forum, Washington, DC, May 1998.

10. Rajagopalan, R. G., Keys, C. N., "Detailed Analysis of the RAH-66 FANTAIL $^{\text {TM }}$ Using CGD”, AHS Journal, October 1997.

11. Leishman, J. G., "Principles of Helicopter Aerodynamics", Cambridge University Press, 2000, ISBN 0521660602.

12. Keys C., Sheffer M., Weiner S., Heminway R., "LH Wind Tunnel Testing: Key to Advanced Aerodynamic Design", AHS $47^{\text {th }}$ Annual Forum, Phoenix, Arizona, May 1991.

13. Pacheco, P. S., "Parallel Programming with MPI", Morgan Kaufmann Publishers, Inc., 1997, ISBN 155860-339-5.

14. Modi, A., Long, L. N., Sezer-Uzol, N., Plassmann P., "Scalable Computational Steering System for Visualization of Large-Scale CFD Simulations", AIAA 2002-2750, AIAA Fluids Conference, St. Louis, 2002.

15. Modi, A., Long, L., Plassmann, P., "RealTime Visualization of Wake-Vortex Simulations using Computational Steering and Beowulf Clusters", Parallel Computing Conference, Portugal, 2002.

16. Hansen, R. P., Long, L. N., "Large Eddy Simulation of a Circular Cylinder on Unstructured Grids", AIAA 2002-0982, AIAA Aerosp. Sciences Meeting, Reno, Jan., 2002.

17. Souliez, F., Long, L., N., Morris, P. J., Sharma, A., "Landing Gear Aerodynamic Noise Prediction using Unstructured Grids", Intl. Jnl of Aeroacoustics, Vol. 1, (2), 2002

18. Long, L. N., Modi, A., "Turbulent Flow and Aeroacoustics Simulations using a Clusters of
Workstations", NCSA Linux Revolution Conference, Illinois, June, 2001.

19. Sharma, A., Long, L. N., "Airwake Simulations on an LPD 17 Ship", AIAA 2001-2589, 15 ${ }^{\text {th }}$ AIAA CFD Conference, Anaheim CA June 2001.

20. Long, L. N. Souliez F., Sharma, A., "Aerodynamic Noise Prediction using Parallel Methods on Unstructured Grids", AIAA 2001-2196, $7^{\text {th }}$ AIAA/CEAS Aeroac. Conference, Maastricht, Netherlands, May 2001.

21. Souliez, F. and Long, L. N., "Computational Simulations of Rotorcraft Fuselage Drag," submitted to the Journal of the American Helicopter Society, April, 2002.

22. Schweitzer. F., "Computational Simulation of Flow around Helicopter", M.S. Thesis, Penn State University, Aerospace Engineering Department, May 1999.

23. Modi, A., "Unsteady Separated Flow Simulations Using a Cluster of Work Stations", M.S. Thesis, Penn State University, Aerosp. Engineering Department, May 1999.

24. Hansen R., "Separated Turbulent Flow", Ph.D. Thesis, Penn State University, Mechanical Engineering Department.

25. Souliez F., "Parallel Methods for Computing Unsteady Separated Flows around Complex Geometries", Ph.D. Thesis, Penn State University, Aerosp. Engr. Dept., August 2002.

26. Modi, A., Long, L. N., "Unsteady Separated Flow Simulations using a Cluster of Workstations", $38^{\text {th }}$ AIAA 2000-0272, AIAA Aerosp. Sciences Meeting, Jan, 2000.

27. http://cocoa2.ihpca.psu.edu/ 